University of South Carolina

Scholar Commons

$12-20-2012$

\title{
Local Filters Limit Species Diversity, but Species Pools Determine Composition
}

Tara K. Rajaniemi

University of Massachusetts - Dartmouth, trajaniemi@umassd.edu

Deborah E. Goldberg

University of Michigan - Ann Arbor

Roy Turkington

University of British Columbia

Andrew R. Dyer

University of South Carolina - Aiken, AndyD@usca.edu

Follow this and additional works at: https://scholarcommons.sc.edu/aiken_biology_geology_facpub

Part of the Biology Commons, Botany Commons, and the Weed Science Commons

\section{Publication Info}

Published in Perspectives in Plant Ecology, Evolution and Systematics, Volume 14, Issue 6, 2012, pages 373-380.

(c) 2012 Elsevier $\mathrm{GmbH}$. All rights reserved. Licensed with a CC-BY-NC-ND license.

Rajaniemi, T. K., Goldberg, D. E., Turkington, R., \& Dyer, A. R. (2012). Local filters limit species diversity, but species pools determine composition. Perspectives in Plant Ecology, Evolution and Systematics, 14(6), 373-380. https://doi.org/10.1016/j.ppees.2012.09.004 inclusion in Faculty Publications by an authorized administrator of Scholar Commons. For more information, please contact digres@mailbox.sc.edu. 
Research article

\title{
Local filters limit species diversity, but species pools determine composition
}

\author{
Tara K. Rajaniemia ${ }^{\mathrm{a}, *}$, Deborah E. Goldberg ${ }^{\mathrm{b}}$, Roy Turkington ${ }^{\mathrm{c}}$, Andrew R. Dyer ${ }^{\mathrm{b}, 1}$ \\ a Biology Department, University of Massachusetts Dartmouth, 285 Old Westport Road, North Dartmouth, MA 02747, USA \\ b Department of Ecology and Evolutionary Biology, University of Michigan, Ann Arbor, MI 48109-1048, USA \\ ${ }^{\mathrm{c}}$ Department of Botany and Biodiversity Research Center, University of British Columbia, Vancouver, BC V6T 1Z4, Canada
}

\section{A R T I C L E I N F O}

\section{Article history:}

Received 27 June 2012

Received in revised form

26 September 2012

Accepted 27 September 2012

\section{Keywords:}

Species interactions

Species richness

Precipitation

Sand dune annuals

Plant density

\begin{abstract}
A B S T R A C T
In a series of three experiments, we tested for effects of species pools, resource stress, and species interactions on four aspects of community structure: species richness, evenness, species composition, and functional group composition. We also examined whether the impacts of species interactions on the community varied with resource availability or species pool. Communities of sand dune annuals grew from seed bank samples collected from two sites in three different years, so that the species pool differed at two levels: the source site and the year of seed bank collection. Communities experienced one of three irrigation treatments and a range of sowing densities, which varied resource supply (stress) and the potential for species interactions, respectively.

Species richness and evenness were most affected by local factors: higher densities and lower water availability decreased species diversity. In contrast, species composition was influenced most by the species pool. Functional group composition had an intermediate response, and was affected by both species pools and local filters.

Resource stress and species interactions strongly filtered species from the community, but the identity of species remaining was variable. Furthermore, the magnitude of species interaction effects on richness and evenness varied with species pools. Thus, the outcome of species sorting among biotic and abiotic environments was dependent on the pool of available species. Contrary to predictions from theory, the effects of species interactions on the community did not vary consistently with resource levels.
\end{abstract}

(c) 2012 Elsevier GmbH. All rights reserved.

\section{Introduction}

The community assembly process has been described as a series of successive filters, each of which limits the set of species in a community (Keddy, 1992; Zobel, 1997; Götzenberger et al., 2012). This concept of community assembly begins with a pool of species present in a region, only a subset of which is able to disperse to a habitat to form the local species pool. Abiotic conditions, such as resource shortage, and biotic interactions, such as competition, eliminate additional species, ultimately leaving the species that form the community. A current challenge in community ecology is to quantify the relative contributions of species pools and various abiotic and biotic filters in structuring communities and to understand how these interact to produce patterns in community structure across environments (Algar et al., 2011; Grace et al., 2011; Belmaker and Jetz, 2012; Götzenberger et al., 2012).

\footnotetext{
* Corresponding author.

E-mail address: trajaniemi@umassd.edu (T.K. Rajaniemi).

1 Present address: Department of Biology and Geology, University of South Carolina-Aiken, Aiken, SC 29801, USA.
}

By examining patterns in natural field vegetation for a community of desert sand dune annuals, we previously showed that species pools, resource availability, and species interactions all affect species richness at different temporal and spatial scales (Rajaniemi et al., 2006). Previous experiments in the same system demonstrated that all three factors significantly affect fitness of individuals (Goldberg et al., 2001) as well as species composition (Rajaniemi et al., 2009). However, we did not quantify the relative magnitudes of effects of the different factors in those reports and therefore could not assess their relative importance. Here, we describe an experiment in which we simultaneously manipulated species pools, resources, and intensity of species interactions to measure their relative effects on multiple aspects of community structure: richness, evenness, species composition, and functional group composition.

In addition to their separate direct effects, species pools and abiotic and biotic filters may also interact in their effects on community structure. The effects of species interactions, in particular, may depend on resource levels. Alternative theories hold that the effects of interactions do not vary along resource gradients (Tilman and Pacala, 1993), are strongest when resources are abundant (Grime, 1977), are strongest when resources are low 
(Goldberg et al., 1999, 2001), or switch from mostly facilitative to mostly competitive as resource stress decreases (Bertness and Callaway, 1994; Maestre et al., 2009). Few previous studies have directly assessed the community-level effects of competition along resource gradients (Rajaniemi et al., 2003; Lenssen et al., 2004). The effects of species interactions may also vary with species pool: the traits of species in the pool form a biotic background or an "interaction milieu" with which an individual must interact (McGill et al., 2006), and different pools should provide different biotic backgrounds.

We studied the effects of species pools, resources, and species interactions on communities of annual plants grown from fieldcollected seed banks, using a series of three similar experiments. Species pool varied in two ways: seed banks came from two source communities representing two different pools, and each experiment used a seed bank collected in a different year, so the identity of the available species varied depending on differential reproductive success of adults in the previous year and survival in the seed bank over multiple years. Resource level was varied by irrigation treatments mimicking rainfall in the two source communities, as well as an intermediate level of rainfall. Finally, we used a community density series (Goldberg et al., 1995, 2001) to vary the intensity of species interactions.

The source communities, experiments, and experimental treatments we analyzed reflect the community assembly process in our study site. The two source communities draw species from a single regional pool, but differ in composition due to the effects of longdistance dispersal and climate patterns (Rajaniemi et al., 2006). In any given year, the species pool in the seed bank reflects reproduction across microsites that vary widely in shoot density and in microclimate (Rajaniemi et al., 2006); therefore, seed banks collected in different years are influenced more by random selection from the source community pool than by particular filters. Within a year, the actual community that emerges in a plot results from abiotic (resource) and biotic (species interactions) filters acting on the species pool present in the seed bank.

We addressed the following two questions:

- What are the relative magnitudes of the effects of species pool, resources, and species interactions on different aspects of community structure (richness, evenness, species composition, and functional group composition)?

- Does the magnitude of the effect of species interactions depend on resource level and/or species pool?

\section{Methods}

\section{System}

The system consisted of annual plants occurring at two semistabilized sand dune sites in Israel - one desert and one coastal community (source sites). Both sites have a Mediterranean climate with a winter growing season. Mean annual precipitation (30-year average, Israeli Meteorological Service) is $110 \mathrm{~mm}$ at the desert site (Holot Mashabim, $31^{\circ} 00^{\prime} \mathrm{N} 34^{\circ} 44^{\prime} \mathrm{E}$ ), and $550 \mathrm{~mm}$ at the Mediterranean coastal site (Caesarea $32^{\circ} 30^{\prime} \mathrm{N} 34^{\circ} 55^{\prime} \mathrm{E}$ ).

At both source sites, in September before the sowing of each experiment, we collected seed bank from the top $2 \mathrm{~cm}$ of sand from at least 60 random plots (Experiment 1 ) or along three 50 - $m$ transects (Experiments 2 and 3 ). The transects were established from randomly located starting points with randomly chosen directions within each source site. Samples were taken continuously along the transects, with the constraint of maintaining $>30 \mathrm{~cm}$ margin from the edge of shrubs. Shortly after collection, the samples from within each source site were combined and then passed through a series of sieves to eliminate the sand. The smallest fraction $(<500 \mu \mathrm{m})$ contained almost no seeds (verified by germination tests) and was not used. The rest of the seed bank was thoroughly mixed to use as the concentrated seed bank, and stored in dry laboratory conditions.

The annual plant communities from the two source sites were grown in a common garden constructed at the Blaustein Institute for Desert Research at Sede Boqer $\left(30^{\circ} 48^{\prime} \mathrm{N} 34^{\circ} 48^{\prime} \mathrm{E}\right.$; MAP $\left.98 \mathrm{~mm}\right)$. The garden comprised multiple trenches ( $2 \mathrm{~m} \times 10 \mathrm{~m} ; 1 \mathrm{~m}$ deep), each accommodating eight $1 \mathrm{~m}^{2}$ plots and eight $0.5 \mathrm{~m} \times 0.5 \mathrm{~m}$ plots, filled with sterile sand. More detailed information on the common garden system can be found in Goldberg et al. (2001).

\section{Experimental design}

We conducted three experiments initiated in three different years; two lasted a single growing season and one lasted two seasons. The basic design for each experiment was a factorial with three to eight different initial community densities $\times$ three irrigation treatments (low, intermediate, and high) $\times$ two source communities (desert and coastal), with replication in multiple blocks (Table 1 ).

A range of initial sowing densities was established by sowing different amounts of homogenized, concentrated seed bank on the surface of the plots, from $1 / 16 \times$ to $8 \times$ average natural density (referred to as $1 \times$ ). This approach allowed us to change the seed density while keeping the initial relative abundances of species constant. The $1 \times$ natural density plots were sown with the mean mass of seed bank that was collected from the equivalent area in the field and were intended to achieve the mean natural density. Increasing sowing density increases the probability that two plants compete for light by shading each other or compete for soil resources by drawing from the same soil volume. It also increases the opportunity for plants to ameliorate stresses by shading the soil to decrease temperatures or reduce evaporation.

Three irrigation treatments were imposed that mimicked aspects of the precipitation regimes of the two source sites, and an intermediate regime. Long-term rainfall records indicate that, on average, the desert and coastal sites receive, respectively, 1.1 and 5.8 times the annual precipitation of the experimental garden site at Sede Boqer. After each naturally occurring rainfall event at Sede Boqer, additional watering was done to maintain these proportional differences, with the intermediate treatment receiving the midpoint of these extremes $(3.45 \times$ precipitation at Sede Boqer).

Because irrigation treatments could only be assigned to entire trenches, we used a nested block design, with three trenches in each block. One trench of each block was assigned randomly to each irrigation regime and the combinations of source and density treatments were then assigned randomly within each trench. Because of limited amounts of available seed bank it was necessary to have different plot sizes. The higher seed bank densities were sown into small $(0.5 \mathrm{~m} \times 0.5 \mathrm{~m})$ plots and the lower densities were sown in the larger $\left(1 \mathrm{~m}^{2}\right)$ plots (Table 1$)$. In Experiments 1 and 3 , natural densities $(1 \times)$ were sown in both large and small plots to assess effects of plot size.

All plots were sown in November by spreading the appropriate amount of seed bank uniformly across the surface of the sand of each plot. The seed bank was then covered by $1 \mathrm{~cm}$ of sterile sand and lightly watered with an equivalent of $5 \mathrm{~mm}$ of rainfall to prevent loss of seed by wind.

Percent cover of each species in the two-year Experiment 3 was estimated at the end of the first season in April 1995, after cessation of natural rainfall and as most species were just beginning to dry after ripening seeds. In May 1995, plots were covered 
Table 1

Sowing and harvest dates, sowing densities, and replication for the three experiments.

\begin{tabular}{|c|c|c|c|c|}
\hline Experiment & Sowing date & Harvest date (length) & Densities (\# replicate plots, size) & $\begin{array}{l}\text { Ambient rainfall ( } \mathrm{mm} \text { per } \\
\text { growing season) }\end{array}$ \\
\hline 1 & November 1993 & $\begin{array}{l}\text { April } 1994 \\
\text { (1 growing season) }\end{array}$ & $\begin{array}{l}1 / 16 \times, 1 / 8 \times(4 \text { large }) \\
1 / 4 \times, 1 / 2 \times(2 \text { large }) \\
1 \times(2 \text { small, } 2 \text { large }) \\
2 \times, 4 \times, 8 \times(2 \text { small })\end{array}$ & 58.05 \\
\hline 2 & November 1996 & $\begin{array}{l}\text { April } 1997 \\
\text { (1 growing season) }\end{array}$ & $\begin{array}{l}1 / 16 \times, 1 / 8 \times, 1 / 4 \times, 1 / 2 \times(3 \text { large }) \\
1 \times, 4 \times(3 \text { small })\end{array}$ & 114.9 \\
\hline 3 & November 1994 & $\begin{array}{l}\text { April } 1996 \\
\text { ( } 2 \text { growing seasons) }\end{array}$ & $\begin{array}{l}1 / 16 \times(12 \text { large }) \\
1 \times(4 \text { small, } 4 \text { large }) \\
4 \times(4 \text { small })\end{array}$ & $139.8,51.35$ \\
\hline
\end{tabular}

by mesh screens to prevent dispersal and seed predation during the summer. Mesh screens were removed in the early fall before initiation of the rainy season. Major branches of the senesced plants were clipped, chopped, and returned to the plots to ensure that seeds remaining on the plants were part of the potentially emerging seed bank. The litter layer was then covered by $1 \mathrm{~cm}$ of fresh sand to prevent seeds from blowing away, and watered as after the initial sowing. This sand layer did not appear to inhibit later germination: watering mixed seeds into the sand layer (R.T., personal observation), and small seeded species such as Ifloga rueppelli germinated in the second growing season.

Aboveground biomass was harvested from each experiment in April, except for a $10 \mathrm{~cm}$ buffer zone around each plot. Individuals in each plot were sorted to species, and the number of shoots of each species was counted. In Experiment 3, percent cover estimates were repeated before harvest.

\section{Statistical analyses}

\section{Adjusting richness and evenness for sample size}

Species richness $(S)$ was quantified as the total number of species in a plot at harvest. Evenness was quantified as E-var (Smith and Wilson, 1996). However, measures of species diversity are sensitive to the number of individuals sampled (Magurran, 1988), and the different plot sizes and density manipulations in the experimental design will produce patterns in shoot number that may obscure responses of diversity to the treatments. Therefore, values of $S$ for each plot were adjusted for sample size, as follows.

We used random sampling from a "null-community pool" to calculate two measures of expected diversity for each plot: the expected species richness and evenness of a plot if diversity were controlled only by shoot number. The null-community pool consisted of all species observed in $1 / 16 \times$ and $1 / 8 \times$ plots in that experiment, along with their total abundances. The lowest density plots were used as the pool because these were expected to be closest to the null community, in which species interactions did not affect composition. The probability of selecting a species from the null-community pool was proportional to its relative abundance in the pool. Expected diversity in a given plot was based on the mean diversity of 500 samples, where each sample consisted of a random draw of $N$ individuals from the pool, with $N=$ the number of individuals observed at harvest in that plot.

Sample-size-adjusted values for diversity were calculated as the deviation of observed richness or evenness from that expected given random sampling from the pool, expressed as a log response ratio $\left(\ln R R_{S}=\ln (\right.$ observed $S /$ expected $S)$ ). $\ln R R$ values were mostly negative, and can be thought of as quantifying the total effects of all factors (other than number of individuals sampled) that constrain species richness or evenness in a plot. To verify that the adjustment removed effects of sample size on $S$, we tested for effects of plot size on $S$ and $\ln \mathrm{RR}_{S}$ in plots with natural $(1 \times)$ sowing density in Experiment 3 . As expected, $S$ was larger in the $1 \mathrm{~m} \times 1 \mathrm{~m}$ plots than in the smaller $(0.5 \mathrm{~m} \times 0.5 \mathrm{~m})$ plots (ANOVA; $F_{1,45}=65.6$, $p<0.001)$, but plot size had no effect on $\ln \mathrm{RR}_{S}\left(F_{1,45}=0.001, p=\right.$ $0.978)$.

\section{Tests for significance of treatment effects}

We tested for treatment effects on richness and evenness using the general linear model function in SPSS v16 (SPSS 2007). We used a split-plot design because each trench had only one level of irrigation. The factors considered were 'trench', 'experiment' (random factors), 'source site', 'sowing density', and 'irrigation' (fixed factors)

To test for effects of treatments on species composition and functional group composition of the community, we used multivariate analyses with PRIMER-E software (Primer-E Ltd., Plymouth, UK). Species were assigned to one of three functional groups: grasses, legumes, and other dicots. Shoot number of each species or functional group was standardized by sample and square-root transformed. Permutational ANOVA (PERMANOVA; Anderson et al., 2008) with a split-plot design was used to test for effects of trench, experiment, source site, sowing density, and irrigation on species composition and on functional group composition.

\section{Magnitude of treatment effects}

To create a metric of the effects of treatments on community structure, we compared mean diversity and assessed community dissimilarity between treatment levels. The effect of species interactions on sample size-adjusted species richness and evenness was calculated as:

density effect $=$ mean $\ln \mathrm{RR}_{\mathrm{HD}}-$ mean $\ln \mathrm{RR}_{\mathrm{ND}}$

where HD represents all high-density plots $(2 \times, 4 \times$, and $8 \times$ initial sowing densities) and ND represents null-density plots $(1 / 16 \times, 1 / 8 \times)$. Null-density plots were expected to have minimal plant-plant interactions, while plots with $2 \times$ to $8 \times$ seed bank densities achieved adult plant densities near the median of field densities. Thus, the density effect quantifies the change in sample size-adjusted $S$ or E-var resulting from increasing the potential for species interactions.

Similarly, the effects of other experimental factors were also calculated as differences in mean sample size-adjusted richness and evenness. These comparisons include plots sown at all densities. All sowing densities were considered relevant to explaining the effects of factors on natural communities in the field, because actual field densities encompass the entire range of sown densities. The irrigation effect $=$ mean $\ln \mathrm{RR}_{\text {low }}-$ mean $\ln \mathrm{RR}_{\text {high }}$; the magnitude of the irrigation effect size is the change in diversity resulting from increased resource stress. Comparison of intermediate and high irrigation treatments showed similar patterns of effects of 
Table 2

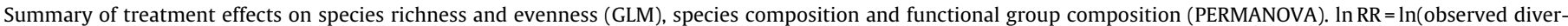

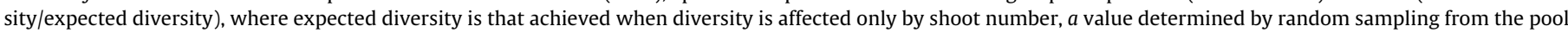
of plants found in null-density plots.

\begin{tabular}{|c|c|c|c|c|c|c|c|c|}
\hline & \multicolumn{2}{|c|}{$\ln \mathrm{RR}(S)$} & \multicolumn{2}{|c|}{ ln RR (E-var) } & \multicolumn{2}{|c|}{ Species composition } & \multicolumn{2}{|c|}{$\begin{array}{l}\text { Functional group } \\
\text { composition }\end{array}$} \\
\hline & $F$ & $p$ & $F$ & $p$ & $F$ & $p$ & $F$ & $p$ \\
\hline Source & 3.062 & 0.212 & 11.327 & 0.043 & 0.223 & 0.686 & 24.657 & 0.001 \\
\hline Irrigation & 14.056 & 0.001 & 1.290 & 0.303 & 27.082 & 0.002 & 27.232 & 0.023 \\
\hline Experiment & 5.656 & 0.056 & 22.173 & 0.001 & 0.038 & 0.963 & 28.807 & 0.001 \\
\hline Density & 3.312 & 0.059 & 1.500 & 0.099 & 1.826 & 0.211 & 3.404 & 0.065 \\
\hline Source $\times$ irrigation & 0.096 & 0.910 & 1.762 & 0.133 & 0.546 & 0.610 & 1.228 & 0.394 \\
\hline Source $\times$ experiment & 1.679 & 0.332 & 41.892 & 0.001 & 1.698 & 0.235 & 6.393 & 0.007 \\
\hline Source $\times$ density & 3.233 & 0.037 & 1.949 & 0.032 & 0.519 & 0.799 & 0.488 & 0.713 \\
\hline Irrigation $\times$ experiment & 0.155 & 0.955 & 1.553 & 0.327 & 0.278 & 0.882 & $<0.001$ & ns \\
\hline Irrigation $\times$ density & 1.130 & 0.379 & 1.348 & 0.069 & 1.252 & 0.310 & 0.831 & 0.622 \\
\hline Experiment $\times$ density & 6.178 & 0.092 & 2.668 & 0.001 & 1.016 & 0.476 & 5.149 & 0.001 \\
\hline Source $\times$ irrigation $\times$ expt & 13.95 & 0.294 & 1.720 & 0.001 & 6.329 & 0.013 & 0.488 & 0.713 \\
\hline Source $\times$ irrigation $\times$ density & 0.863 & 0.603 & 1.396 & 0.046 & 5.071 & $<0.001$ & 1.693 & 0.171 \\
\hline Source $\times$ experiment $\times$ density & 1.052 & 0.440 & 1.553 & 0.001 & 14.568 & $<0.001$ & 1.436 & 0.170 \\
\hline Irrigation $\times$ experiment $\times$ density & 0.808 & 0.652 & 0.593 & 0.999 & 3.726 & 0.007 & 0.872 & 0.568 \\
\hline Source $\times$ irrigation $\times$ experiment $\times$ density & 0.844 & 0.621 & 0.621 & 0.999 & 0.265 & 0.997 & 0.576 & 0.863 \\
\hline
\end{tabular}

Significant effects $(p<0.05)$ are shown in bold.

those treatments on community structure (not shown). The source effect $=$ mean $\ln R_{\text {desert }}-$ mean $\ln R_{\text {coastal }}$; its value measured the change in diversity due to drawing from the source pool from the desert site relative to the coastal site. The desert site was drier and also more species-rich (Rajaniemi et al., 2006).

Two comparisons were made among the experiments: the experiment lasting two growing seasons was compared to the two single-season experiments, and the two single-season experiments were compared. The effect of experiment duration = mean $\ln R R_{\text {expt } 3-\text { mean }} \ln R R_{\text {expts } 1 \& 2}$; this measures the effect of the longer experiment, relative to the shorter ones. While we refer to this comparison as experiment duration, Experiment 3 was also initiated in a different year than either of the other two experiments and so also likely has a different seed bank. The effect of experiment year $=$ mean $\ln \mathrm{RR}_{\text {expt } 1}-$ mean $\ln \mathrm{RR}_{\text {expt } 2 \text {. }}$

To calculate analogous treatment effect sizes on species and functional group composition, we pooled the plants present in all the plots within a treatment, and then calculated Bray-Curtis dissimilarity between groups of interest. For example, the effect of source community is equal to the dissimilarity between a community consisting of all plants observed in plots from the coastal source and a community of all plants observed in plots from the desert source. Bray-Curtis dissimilarity values were scaled to fall between 0 (communities identical) and 100 (no species shared). Species abundances were standardized by sample and square-root transformed (to downweight the contributions of dominant species) before analysis. For effects other than source, dissimilarity values were determined separately for the two source communities, because the large differences in composition due to source obscured the effects of other factors. Thus, four effects were calculated for each source community: density effect=dissimilarity between pooled high-density plots and pooled null-density plots; irrigation effect = dissimilarity between pooled high-irrigation plots and pooled low-irrigation plots; effect of experiment duration=dissimilarity between pooled plots from Experiment 3 and pooled plots from Experiments 1 and 2; and effect of experiment year=dissimilarity between pooled plots from Experiment 1 and pooled plots from Experiment 2.

To visualize how the effects of species interactions depended on other treatments, we first identified significant interactions of sowing density with other factors from GLM or PERMANOVA (see above, Tests for significance of treatment effects, and Table 2). We then calculated effects of initial density, as described above, for subsets of the data, separating levels of factors that interacted with density.

\section{Experiment effects}

The three experiments differed in species pools (based on the composition of the seed bank collected that year), natural precipitation (Table 1), and duration. We conducted additional analyses to examine the effects of each of these differences on community structure.

To test the effects of differences in rainfall, we repeated the GLM and PERMANOVA analyses with total water (natural rainfall plus irrigation) as a covariate, replacing the irrigation factor. To address the effects of experiment duration, we examined changes in community structure between years in Experiment 3. As with other comparisons of species richness, we needed to take differences in total abundance into account to eliminate sampling effects. However, we had cover rather than shoot density data for the first year of Experiment 3, so we could not calculate sample-size adjusted richness or evenness. Instead, we used the observed cover-species relationship from year 1 to predict how many species each plot should be expected to gain (or lose) in year 2, based on its increase (or decrease) in cover. We then compared actual change in species richness to expected change in species richness. Evenness was uncorrelated with total cover in this experiment, so we compared evenness between years without any adjustment. We also used PERMANOVA to test for changes in functional group composition and species composition between years, based on percent cover.

\section{Results}

Source site, density, and irrigation all had significant effects on species richness, and the effect of experiment was marginally significant $(p=0.056)$. All four treatments had significant effects on evenness, species composition, and functional group composition (Table 2). In cases where treatment main effects were not significant, each factor appeared in a significant interaction. We first discuss the average effects of separate treatments and then consider treatment interactions, focusing on the interactions of the sowing density treatment (which manipulated the potential for species interactions) with other treatments. Although the analyses reported in Table 2 include all sowing densities, we illustrate 


\section{a. Species richness}

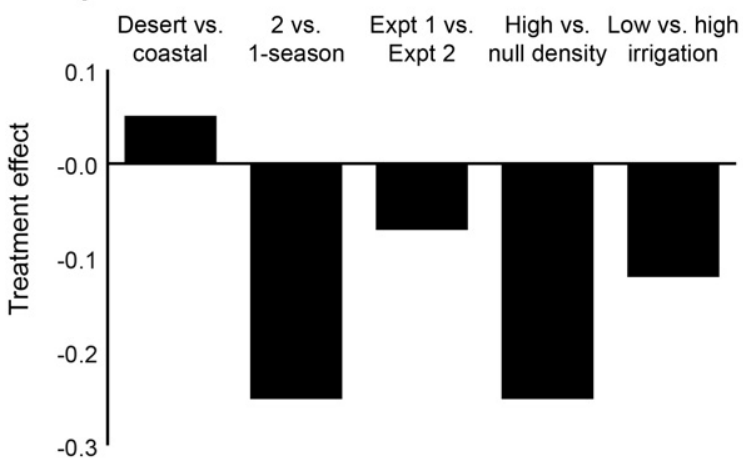

b. Evenness

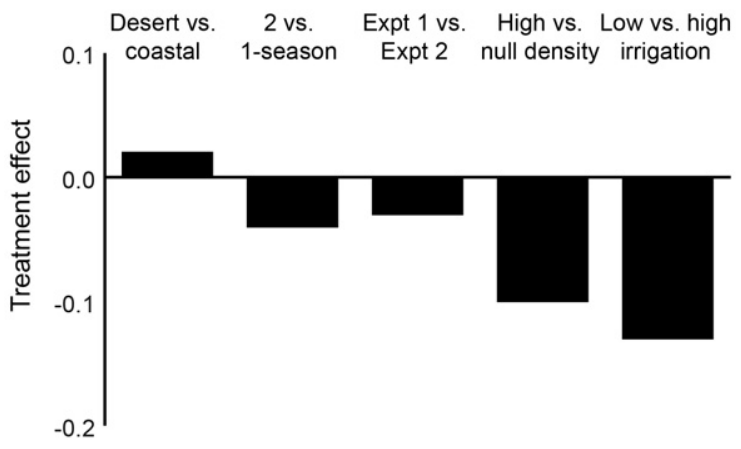

\section{c. Species composition}

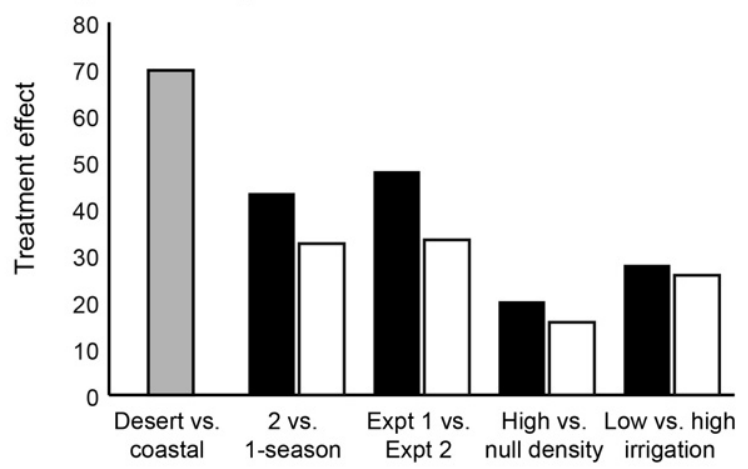

d. Functional group composition

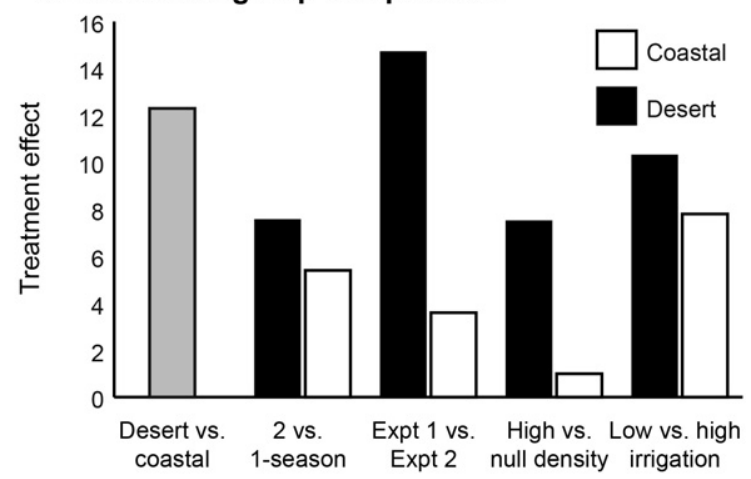

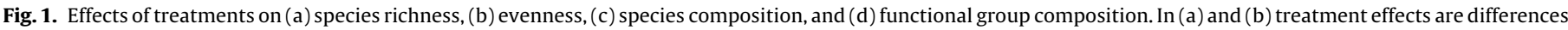

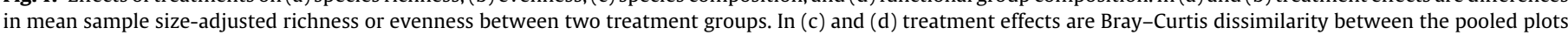
in the two treatment groups. Effects other than source on composition are calculated separately for the two source communities.

patterns in density effects (Figs. 1 and 3) by focusing on the effect of high densities relative to null densities on the community.

\section{Treatment effects on community structure}

The relative magnitude of effects of the different experimental factors differed considerably among the measures of community structure. Density (species interactions) and irrigation treatments had the greatest effects on species richness and evenness. Both measures of diversity declined with increasing density, and therefore increased potential for species interactions (Fig. 1a), and with fewer resources (low relative to high irrigation; Fig. 1b). Source community had only a small effect, with higher richness and evenness in the desert source community. Experiment 3, which lasted two growing seasons, also had lower richness than the singlegrowing-season experiments.

Functional group composition was affected most strongly by source community, experiment (particularly between the two single-growing season experiments in the desert community), and irrigation (Fig. 1c, Fig. 2). Grasses were more common in the coastal community, which is the more mesic habitat; in Experiment 1; and at high density and low irrigation (Fig. 2 and Table 2).

Source community had the greatest effect on species composition, followed by experiment duration and experiment year. Density and irrigation had smaller effects (Fig. 1d).

\section{Determinants of the magnitude of density effects on community structure}

The effects of species interactions on all measures of community structure always depended on one or both of the factors reflecting differences in species pools, as indicated by the lack of any significant main effects of density but the many statistically significant interactions involving density and source community or experiment or both (Table 2). The effects of species interactions depended less often on irrigation, and without any consistent patterns.

The effect of sowing density on species richness interacted with source site: species interactions reduced richness more in the coastal species pool (Table 2 and Fig. 3a). For evenness, sowing density interacted with source, experiment, and irrigation in multiple three-way interactions (Table 2). However, few clear patterns were associated with these interactions (Fig. 3b). While species interactions tended to reduce evenness (Fig. 1b), they increased evenness

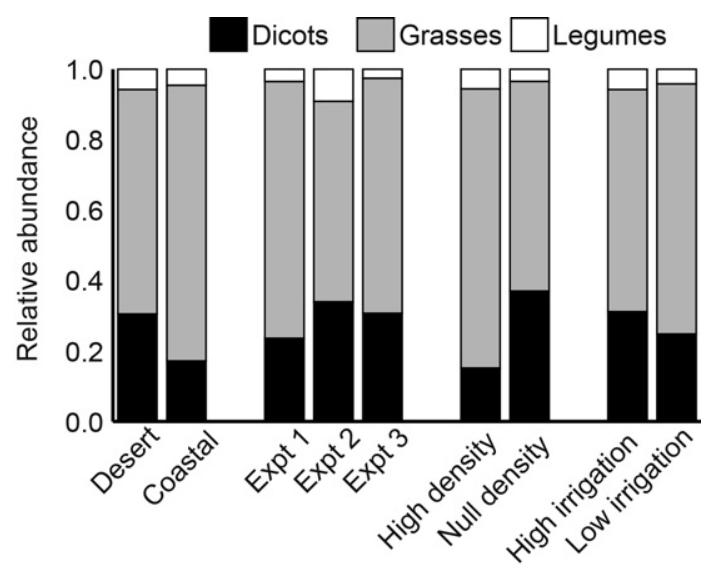

Fig. 2. Mean relative abundance (based on number of individuals) of each functional group, by treatment. 
a. Species richness

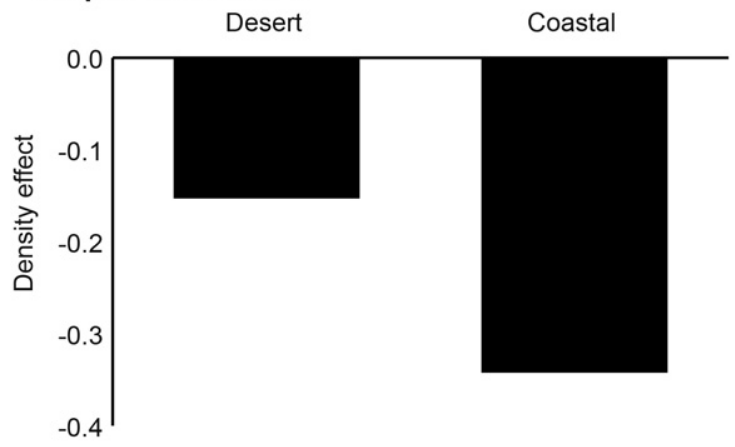

\section{b. Evenness}

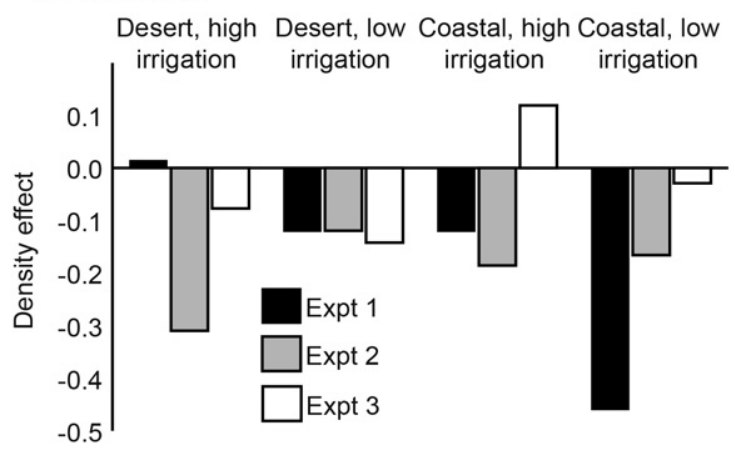

c. Species composition

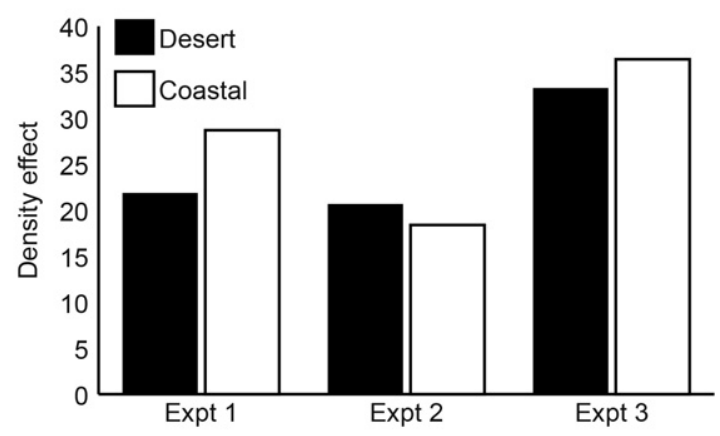

d. Functional group composition

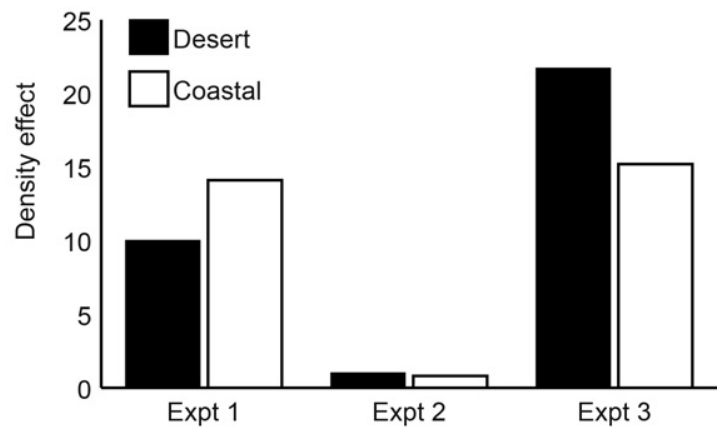

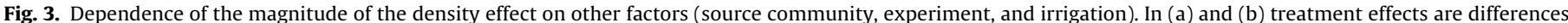

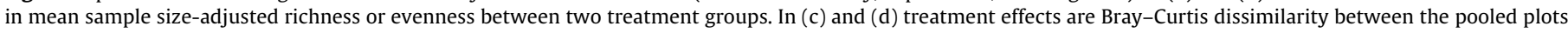
in the two treatment groups. Only statistically significant interactions (Table 2) are shown.

in a few combinations of species pool, experiment, and irrigation treatment (Fig. 3b).

The effect of sowing density on functional group composition depended on experiment (Table 2), with stronger effects in Experiments 1 and 3 (Fig. 3b).

For species composition, the effect of sowing density depended on both source community and experiment (Table 2): density affected species composition more in the desert community in Experiments 1 and 3, but more in the coastal community in Experiment 2 (Fig. 3d). Sowing density also interacted with source and irrigation (Table 2 ), but this interaction resulted largely from differences between low densities $(1 / 2 \times$ and $1 / 4 \times)$ and high densities $(>1 \times)$ (not shown), not from null and high densities.

\section{Experiment effects}

Experiment had additional effects on the community beyond those resulting from differences in rainfall. When total water availability was entered into analyses as a covariate, the effect of experiment remained significant for species richness $\left(F_{2,347}=19.3\right.$, $p<0.001$ ), evenness (source $\times$ experiment $\times$ density interaction, $\left.F_{7,347}=3.18, p=0.003\right)$, functional group composition $\left(F_{2,347}=40.2\right.$, $p=0.001)$, and species composition $\left(F_{2,347}=51.4, p=0.001\right)$.

In Experiment 3, all measures of community structure changed between years. On average, although the number of species in a plot increased with time, the increase was less than would be expected based on plant abundance (paired $t$-test, $t_{1,143}=2.03$, $p=0.044$ ). Thus, after correcting richness for abundance, species richness decreased with time. Evenness also decreased over time $\left(t_{138}=6.69, p<0.001\right)$. Both functional group composition and species composition shifted significantly between years
(PERMANOVA; $F_{1,279}=14.4, p=0.002$ for functional groups and $F_{1,279}=12.8, p=0.001$ for species). However, the magnitude of the year effect in both cases was small (Bray-Curtis dissimilarity $=10.1$ and 27.6, respectively).

\section{Discussion}

The experiments described here manipulated species interactions (by varying sowing density), resources (by irrigation treatment), and species pools (different source communities within experiments, as well as different seed banks from those communities across experiments) in a community of sand dune annuals. We then compared the effects of each of these factors on four measures of community structure: species richness and evenness, species composition, and functional group composition. Species richness and evenness were most affected by local factors: higher densities and lower water availability decreased species diversity. In contrast, species composition was influenced most by the species pool. The effects of species interactions on the community did not vary consistently with resource levels, but they were dependent on the identity of the species pool.

\section{Interpreting experiment effects}

Because we collected the seed bank for the experiments in different years and carried out those experiments in different years, they differed in species pool, as well as in the weather during the experiment. Experiments 1 and 2 took place in years differing in rainfall and temperature, but incorporating ambient rainfall into our analyses did not eliminate the effect of experiment. Experiment 1 took place in a year with slightly higher temperatures 
than Experiment 2, and had lower species richness. In contrast, across years in natural vegetation, we found that species richness increased as the growing season minimum temperature increased (Rajaniemi et al., 2006). Thus differences in species pool remain the simplest explanation for the differences in species and functional group composition between Experiments 1 and 2 .

Experiment 3 also differed in duration from the other two experiments. Successional dynamics do not account for the distinct differences in species composition between the single-season experiments and the two-season experiment, because the change in composition between years was small. A pattern of increasing cover and decreasing species richness and evenness over time suggests that Experiment 3 may have lower diversity due to successional dynamics: each plot lost rare species in the second year due to failures of reproduction in the first year. As long as different plots lost different species, these losses would have little effect on the overall species pool or on diversity values expected based on random sampling from that pool, but would nevertheless reduce the observed species richness and evenness and therefore $\ln R$ R. Had those species been lost in the same way from small areas in the field, seeds from adjacent areas would have been available to maintain the species in the community. In the experiment, local dispersal was restricted and species were lost. Therefore, the (negative) experiment duration effect on richness may be interpreted as a (positive) effect of local dispersal on richness under field conditions.

\section{Effects of local filters and species pools on community structure}

Our first objective was to determine which factors have the greatest effects on each measured aspect of community structure. Species richness and evenness were consistently reduced by more intense species interactions and by lower resources, with the greatest diversity found in plots with low sowing densities and high irrigation. In previous studies, reducing the potential for species interactions has consistently increased diversity, in systems as diverse as deserts (Goldberg and Estabrook, 1998), grasslands (Rajaniemi et al., 2003; Rajaniemi, 2011), and communities of bryophytes (Zamfir and Goldberg, 2000). Species richness also declined over time in Experiment 3, indicating that a third local filter, small-scale dispersal, contributes to limits on richness. The role of dispersal in limiting diversity has also been demonstrated by seed-addition experiments (Myers and Harms, 2009). While species pools did have detectable effects on richness and evenness, these effects were smaller in magnitude than the effects of local factors, consistent with structural equation models that show stronger effects of local factors than the size of regional species pools on local richness (Harrison et al., 2006; Grace et al., 2011).

Species composition, in contrast, was dependent on the available species pool (Patterson and Brown, 1991; Butaye et al., 2002), with large effects of both source community and experiment. Functional group composition had an intermediate response, in which species pool and irrigation both had strong effects.

The large effects of local filters on species richness suggest strong species sorting along environmental gradients. Our system has several characteristics which meta-community theory predicts are associated with strong species sorting: spatial environmental variability is high, species pools have high functional diversity (Questad and Foster, 2008), and dispersal is sufficient for species to reach suitable sites (Leibold and Norberg, 2004; Foster et al., 2011).

At the same time, the small effects of local filters on species composition suggest that the outcome of any species sorting was highly dependent on species pools. There was no evidence, for example, that experiments converged to a similar set of drought-tolerant species under low irrigation, or to a similar set of good competitors at high sowing density, which would have produced a large, significant effect of irrigation or density on species composition (Fig. 1 and Table 2). Surprisingly, species pools had large effects on species composition even though pools overlapped a great deal: $84 \%$ of desert species and $78 \%$ of coastal species were also observed in the other source community, and within a source community $61-90 \%$ of the species in a single experiment were also present in at least one other experiment.

The weak effects of local filters on species composition might represent a sampling effect if the best-adapted species to a given set of water and competitive conditions are not present in every pool. On the other hand, this pattern might mean that the interaction milieu (McGill et al., 2006) matters: which species is the best competitor depends on the other species with which they compete. Similarly, which species best tolerate drought could depend on the other species present as long as their densities are sufficiently high (as they frequently are in the field) to permit some competition or facilitation. Consistent with the idea that the "best" species are contingent on the interaction milieu, we have not succeeded in identifying particular species as good competitors or good stresstolerators in this system. Principal components analysis does not reveal a consistent set of species associated with low irrigation or high sowing density (Rajaniemi et al., 2009).

\section{Effects of resources and species pools on species interactions}

Our second question was whether the effects of species interactions on community structure depend on resource levels or species pools. An enduring question in community ecology has been whether the effects of competition and facilitation change along resource gradients (Maestre et al., 2009), although the great majority of studies have focused on effects on individual growth rather than on community structure, as in this study (Grace, 1991; Goldberg et al., 1999; Craine, 2005; Reynolds and Rajaniemi, 2007). Surprisingly, we saw few cases in which the community-level effects of interactions changed with irrigation (small effects on evenness only), and no strong or consistent patterns. Similarly, in a three-year experiment in this system, we found that effects of sowing density on species composition did not change with irrigation (Rajaniemi et al., 2009).

The identity of the species pool also mediated the effects of species interactions. In the previous section, we discussed how the outcome of species interactions might vary among pools to influence community composition. We also found that species interactions had a stronger effect on species richness in the coastal community. Many previous studies have investigated the effects of the size of the species pool on richness - that is, whether diversity is dispersal-limited - and how dispersal limitation may interact with competition (Grace, 2001; Foster and Dickson, 2004; Houseman and Gross, 2006). In our experiments, on the other hand, the size of the species pool was similar between source communities (in any given experiment, there were three to five more species in the desert source pool than in the coastal source pool), while the identities of the species in the pool differed. Knowledge of species' functional traits may help explain why the effects of species interactions on richness differ between source communities. For example, competition may be more intense among coastal species if they share greater trait similarity than desert species (Cornwell and Ackerly, 2009; Götzenberger et al., 2012). Alternatively, species may differ in their potential to influence the rest of the community through competition (e.g. Goldberg and Landa, 1991; Keddy et al., 1994), such that the overall intensity of interactions depends on which species are present. 


\section{Implications}

In this system, local filters - water availability, species interactions, and small-scale dispersal - strongly limit species richness in small plots. On the other hand, the effects of local processes on particular species are highly contingent on the pool of species available in that small plot, such that only the processes that determine the species pool have strong impacts on species composition. In our experimental setting, the species pools in replicate plots of the same experiment were constrained to be similar, due to the homogenization of seed bank. We would expect greater variation in the seed bank among locations in the field (Ellner and Shmida, 1981; Lortie and Turkington, 2002), resulting in greater variation in adult species composition among plots with similar abiotic conditions and seed densities. Thus, although species interactions and resource stress limit alpha diversity, beta diversity and gamma diversity should be high.

The system of desert dune annuals we investigated exists in an environment with high variation in microtopography that influences the number of seeds settling (Reichman, 1984) and soil moisture (Svoray et al., 2007). The variation among treatments in our experiment mimics this natural variation in conditions. The pool of species represented by the seeds settling in an area will depend on the reproductive success of each species in previous years as well as random dispersal (Ellner and Shmida, 1981; Lortie and Turkington, 2002); this variation is reflected in our different species pools from different experiments. This combination of variation in local conditions with variation in the species pool has the potential to maintain high species diversity in the system despite the strong controls we observed on species richness at the plot scale.

\section{Acknowledgements}

Financial support was provided by the US-Israel BiNational Science Foundation (BSF 91-00179 to D.E.G. and Linda OlsvigWhittaker), the National Science Foundation (DEB 96-2973 to D.E.G., R.T., and Jessica Gurevitch), and the Natural Sciences and Engineering Research Council of Canada (to R.T.). Rachel MacKay and Mike Treberg provided statistical help. The manuscript was greatly improved by comments by Jim Grace and an anonymous reviewer. This is publication no. 781 of the Mitrani Department of Desert Ecology.

\section{References}

Algar, A.C., Kerr, J.T., Currie, D.J., 2011. Quantifying the importance of regional and local filters for community trait structure in tropical and temperate zones. Ecology 92, 903-914.

Anderson, M.J., Gorley, R.N., Clarke, R., 2008. PERMANOVA+ for PRIMER: Guide to Software and Statistical Methods. Primer-E Ltd., Plymouth, UK.

Belmaker, J., Jetz, W., 2012. Regional pools and environmental controls of vertebrate richness. Am. Nat. 179, 512-523.

Bertness, M.D., Callaway, R., 1994. Positive interactions in communities. Trends Ecol. Evol. 9, 191-193.

Butaye, J., Jacquemyn, H., Honnay, O., Hermy, M., 2002. The species pool concept applied to forests in a fragmented landscape: dispersal limitation versus habitat limitation. J. Veg. Sci. 13, 27-34

Cornwell, W.K., Ackerly, D.D., 2009. Community assembly and shifts in plant trait distributions across an environmental gradient in Coastal California. Ecol. Monogr. 79, 109-126.

Craine, J.M., 2005. Reconciling plant strategy theories of Grime and Tilman. J. Ecol. 93, 1041-1052.

Ellner, S., Shmida, A., 1981. Why are adaptations for long-range seed dispersal rare in desert plants? Oecologia 51, 133-144

Foster, B.L., Dickson, T.L., 2004. Grassland diversity and productivity: the interplay of resource availability and propagule pools. Ecology 85, 1541-1547.

Foster, B.L., Questad, E.J., Collins, C.D., Murphy, C.A., Dickson, T.L., Smith, V.H., 2011. Seed availability constrains plant species sorting along a soil fertility gradient. J. Ecol. 99, 473.
Goldberg, D.E., Estabrook, G.F., 1998. Separating the effects of number of individuals sampled and competition on species diversity: an experimental and analytic approach. J. Ecol. 86, 983-988.

Goldberg, D.E., Landa, K., 1991. Competitive effect and response: hierarchies and correlated traits in the early stages of competition. J. Ecol. 79, 1013-1030.

Goldberg, D.E., Rajaniemi, T., Gurevitch, J., Stewart-Oaten, A., 1999. Empirica approaches to quantifying interaction intensity: competition and facilitation along productivity gradients. Ecology 80, 1118-1131.

Goldberg, D.E., Turkington, R., Olsvig-Whittaker, L., 1995. Quantifying the community-level consequences of competition. Folia Geobot. Phytotx. 30 231-242.

Goldberg, D.E., Turkington, R., Olsvig-Whittaker, L., Dyer, A.R., 2001. Density dependence in an annual plant community: variation among life history stages. Ecol. Monogr. 71, 423-446.

Götzenberger, L., de Bello, F., Bråthen, K.A., Davison, J., Dubuis, A., Guisan, A., Lepš, J., Lindborg, R., Moora, M., Pärtel, M., Pellissier, L., Pottier, J., Vittoz, P., Zobel, K. Zobel, M., 2012. Ecological assembly rules in plant communities - approaches, patterns and prospects. Biol. Rev. 87, 111-127.

Grace, J.B., 1991. A clarification of the debate between Grime and Tilman. Funct. Ecol. 5, 583-587.

Grace, J.B., 2001. The roles of community biomass and species pools in the regulation of plant diversity. Oikos 92, 193-207.

Grace, J.B., Harrison, S., Damschen, E.I., 2011. Local richness along gradients in the Siskiyou herb flora: R.H. Whittaker revisited. Ecology 92, 108-120.

Grime, J.P., 1977. Evidence for existence of three primary strategies in plants and its relevance to ecological and evolutionary theory. Am. Nat. 111, 1169-1194.

Harrison, S., Safford, H.D., Grace, J.B., Viers, J.H., Davies, K.F., 2006. Regional and local species richness in an insular environment: serpentine plants in California. Ecol. Monogr. 76, 41-56.

Houseman, G.R., Gross, K.L., 2006. Does ecological filtering across a productivity gradient explain variation in species pool-richness relationships? Oikos 115, $148-154$.

Keddy, P.A., 1992. Assembly and response rules: two goals for predictive community ecology. J. Veg. Sci. 3, 157-164.

Keddy, P.A., Twolan-Strutt, L., Wisheu, I.C., 1994. Competitive effect and response rankings in 20 wetland plants: are they consistent across three environments? J. Ecol. 82, 635-643.

Leibold, M.A., Norberg, J., 2004. Biodiversity in metacommunities: plankton as complex adaptive systems? Limnol. Oceanogr. 49, 1278-1289.

Lenssen, J.P.M., van de Steeg, H.M., de Kroon, H., 2004. Does disturbance favour weak competitors? Mechanisms of changing plant abundance after flooding. J. Veg. Sci. 15, 305-314.

Lortie, C.J., Turkington, R., 2002. The small-scale spatiotemporal pattern of a seed bank in the Negev desert, Israel. Ecoscience 9, 407-413.

Maestre, F.T., Callaway, R.M., Valladares, F., Lortie, C.J., 2009. Refining the stressgradient hypothesis for competition and facilitation in plant communities. J. Ecol. 97, 199-205.

Magurran, A.E., 1988. Ecological Diversity and its Measurement. Princeton University Press, Princeton, NJ.

McGill, B.J., Enquist, B.J., Weiher, E., Westoby, M., 2006. Rebuilding community ecology from functional traits. Trends Ecol. Evol. 21, 178.

Myers, J.A., Harms, K.E., 2009. Seed arrival, ecological filters, and plant species richness: a meta-analysis. Ecol. Lett. 12, 1250-1260.

Patterson, B.D., Brown, J.H., 1991. Regionally nested patterns of species composition in granivorous rodent assemblages. J. Biogeogr. 18, 395-402.

Questad, E.J., Foster, B.L., 2008. Coexistence through spatio-temporal heterogeneity and species sorting in grassland plant communities. Ecol. Lett. 11, 717-726.

Rajaniemi, T.K., 2011. Competition for patchy resources reduces community evenness. Oecologia 165, 169-174.

Rajaniemi, T.K., Allison, V.J., Goldberg, D.E., 2003. Root competition can cause a decline in diversity with increased productivity. J. Ecol. 91, 407-416.

Rajaniemi, T.K., Goldberg, D.E., Turkington, R., Dyer, A.R., 2006. Quantitative partitioning of regional and local processes shaping regional diversity patterns. Ecol. Lett. 9, 121-128.

Rajaniemi, T.K., Turkington, R., Goldberg, D., 2009. Community-level consequences of species interactions in an annual plant community. J. Veg. Sci. 20, 836-846.

Reichman, O.J., 1984. Spatial and temporal variation of seed distributions in Sonoran Desert soils. J. Biogeogr. 11, 1-11.

Reynolds, H.L., Rajaniemi, T.K., 2007. Plant interactions: competition. In: Functional Plant Ecology. CRC Press, Boca Raton, FL, pp. 457-480.

Smith, B., Wilson, J.B., 1996. A consumer's guide to evenness indices. Oikos 76, 70-82.

Svoray, T., Mazor, S., Bar (Kutiel), P., 2007. How is shrub cover related to soil moisture and patch geometry in the fragmented landscape of the northern Negev Desert? Landscape Ecol. 22, 105-116.

Tilman, D., Pacala, S.W., 1993. The maintenance of species richness in plant communities. In: Species Diversity in Ecological Communities: Historical and Geographic Perspectives. University of Chicago Press, Chicago, pp. 13-25.

Zamfir, M., Goldberg, D.E., 2000. The effect of initial density on interactions between bryophytes at individual and community levels. J. Ecol. 88, 243-255.

Zobel, M., 1997. The relative role of species pools in determining plant species richness: an alternative explanation of species coexistence? Trends Ecol. Evol. 12, 266-269. 